\title{
(2) OPEN ACCESS \\ Risk factors for previously undiagnosed primary open-angle glaucoma: the EPIC-Norfolk Eye Study
}

\author{
Michelle P Y Chan 다, ${ }^{1}$ Anthony P Khawaja 다, ${ }^{2,3}$ David C Broadway, ${ }^{4}$ Jennifer Yip ${ }^{5}$ \\ Robert Luben (10), ${ }^{6}$ Shabina Hayat, ${ }^{6}$ Tunde Peto (ㄷ) ${ }^{7}$ Kay-Tee Khaw, ${ }_{1}^{6}$ Paul J Foster ${ }^{2}$
}

${ }^{1} \mathrm{UCL}$ Institute of

Ophthalmology, UCL, London, UK

${ }^{2}$ NIHR Moorfields Biomedical Research Centre \& UCL Institute of Ophthalmology, London, UK ${ }^{3}$ MRC Epidemiology Unit, University of Cambridge, Cambridge, UK

${ }^{4}$ Department Ophthalmology, Norfolk \& Norwich University Hospital, Norwich, UK

${ }^{5}$ Clinical Research Department, International Centre for Evidence on Disability, London, UK

${ }^{6}$ Department of Public Health and Primary Care, University of Cambridge, Cambridge, UK ${ }^{7}$ Centre for Public Health, Blackwell's Queen's University Belfast, Belfast, UK

\section{Correspondence to}

Michelle P Y Chan, UCL Institute of Ophthalmology, UCL, London EC1V 9EL, UK;

michelle.chan@doctors.org.uk

Received 21 October 2020 Accepted 5 June 202
Check for updates

(c) Author(s) (or their employer(s)) 2021. Re-use permitted under CC BY. Published by BMJ.

To cite: Chan MPY, Khawaja AP, Broadway DC, et al. Br J Ophthalmol Epub ahead of print: [please include Day Month Year]. doi:10.1136/

bjophthalmol-2020-317718

\begin{abstract}
Background and aim Undiagnosed glaucoma is an invisible but important public health issue. At least half of glaucoma cases are estimated to be undiagnosed in western populations. The aim of this study is to examine risk factors for previously undiagnosed primary openangle glaucoma (POAG).

Design Cross-sectional study within the European Prospective Investigation of Cancer-Norfolk Eye Study, a large-scale cohort study in the UK.

Participants 314 study participants with POAG in either eye.

Methods Logistic regression was used to examine associations with previously undiagnosed POAG compared with previously diagnosed POAG. The factors examined included sociodemographic, ocular, physical and economic factors that could be barriers to eye care access.
\end{abstract}

Results 217 participants had previously diagnosed POAG and 107 participants were newly diagnosed with POAG during the study. After adjusting for covariables, the factors significantly associated with previously undiagnosed POAG were: a lower pretreatment intraocular pressure (IOP) (OR $0.71 / \mathrm{mm} \mathrm{Hg}, 95 \% \mathrm{Cl} 0.63$ to $0.80, \mathrm{p}<0.0001$ ), and to have reported no problems with their eyesight (OR $0.03,95 \% \mathrm{Cl} 0.01$ to 0.10 , $\mathrm{p}<0.0001$ ).

Conclusions The risk factors for previously undiagnosed POAG identified in this study highlight the over-reliance on IOP level in glaucoma screening and the risk of missing glaucoma among lower IOP cases. It also suggests a role in improving glaucoma awareness in the community.

\section{INTRODUCTION}

Undiagnosed glaucoma is an invisible yet sizeable public health issue. Eye surveys conducted in developed western countries have consistently shown that at least half of glaucoma cases are previously undiagnosed. ${ }^{12}$ Published studies have described the clinical features and risk factors of undiagnosed glaucoma compared with previously known cases, ${ }^{3-5}$ which include lower education attainment, ${ }^{3}$ not having seen an ophthalmologist in the prior year ${ }^{45}$ or seeing an optometrist rather than an ophthalmologist. ${ }^{3} 5$ There are also reasons to suspect that the clinical features and severity of glaucoma may differ between previously diagnosed and patients with undiagnosed glaucoma. The features shown to be significant for undiagnosed glaucoma are: smaller vertical cup to disc ratio, a negative family history of glaucoma, ${ }^{4}$ presence of visual field detect, ${ }^{5}$ lower mean baseline intraocular pressure (IOP) and baseline hyperopia. ${ }^{3}$ The aim of this study was to examine the associations with previously undiagnosed primary open-angle glaucoma (POAG) in the European Prospective Investigation of Cancer (EPIC)-Norfolk Eye Study, a large British community cohort, focusing on the potential roles of ocular features, physical factors and social barriers to eye care access in undiagnosed POAG.

\section{METHODS \\ Study design}

The EPIC study is a pan-European multi-cohort study, designed to investigate the lifestyle determinants of cancer risks. The EPIC-Norfolk cohort was established in the city of Norwich and the surrounding rural and urban areas, in the eastern English county of Norfolk, between 1993 and 1997. ${ }^{6}$ A total of 30445 men and women aged 40-79 years were recruited at a baseline survey from the databases of 35 general practices. The predominant ethnicity of the cohort was white, and included individuals across the range of socioeconomic status and educational achievements. The EPIC-Norfolk Eye Study was carried out between 2004 and 2011 when ophthalmic data were collected from 8623 participants.

Detailed descriptions of the study design ${ }^{7}$ and glaucoma diagnosis ${ }^{8}$ of the EPIC-Norfolk Eye Study have been reported previously. In brief, all subjects were examined systematically in a screening test, which included tonometry (ORA; Reichert Corporation, Philadelphia, USA), optic nerve head assessment (fundus photos and Heidelberg Retina Tomograph II) and peripapillary nerve fibre layer assessment with scanning laser polarimetry (GDxVCC, Zeiss, Dublin, California, USA). A 24-2 central threshold visual field test (Humphrey 750i Visual Field Analyzer, Carl Zeiss Meditech, Welwyn Garden City, UK) was performed in participants with abnormal findings suspicious of glaucoma on HRT or GDx-VCC, and in 1 out of 10 subjects with normal findings. Subjects with abnormal findings who met a set of predefined criteria designed to detect glaucoma were referred to the Eye Department of the Norfolk and Norwich University Hospital for a definitive eye examination by a consultant ophthalmologist with a specialist interest in glaucoma (DCB). Full details of these criteria were published previously. ${ }^{7}$ Glaucoma was defined as the presence of structural optic disc abnormalities and visual field loss, with no other explanations for the disc and field appearances. POAG is defined as 
Box 1 List of potential risk factors examined in the study

\author{
Sociodemographic factors \\ - Age, sex. \\ - Social class by occupation. \\ - Highest educational qualification. \\ - Employment status. \\ - Self-reported financial status. \\ Systemic factors \\ - Systolic blood pressure. \\ - Diastolic blood pressure. \\ - Body mass index. \\ - Diabetes status. \\ Ocular risk factors \\ - Glaucoma type. \\ - Goldmann-correlated IOP of the glaucomatous eye. \\ - Higher cup/disc ratio (CDR) on disc photos of either eye. \\ - CDR asymmetry. \\ - Axial length. \\ - Visual field (mean deviation). \\ - Central corneal thickness. \\ Proxy factors for eye care seeking behaviour \\ - Self-reported family history of glaucoma (in any blood \\ relation). \\ - Self-reported glasses/ contact lens wear (yes/no). \\ - Self-reported eyesight problem (yes/no/don't know). \\ - Previous cataract surgery in either eye. \\ - Maximum absolute refractive error of either eye. \\ - Worse visual acuity of either eye. \\ - Self-reported health status (excellent or very good/good/fair/ \\ poor).
}

glaucoma in the presence of open anterior angles with no known secondary causes. The differentiation of high tension glaucoma (HTG) and normal tension glaucoma (NTG) was based on IOP level before glaucoma treatment commenced. HTG was defined as untreated IOP $>24 \mathrm{~mm} \mathrm{Hg}$ on one occasion, or $>21 \mathrm{~mm} \mathrm{Hg}$ on at least two separate occasions or on diurnal IOP phasing. NTG was defined as untreated IOP $\leq 21 \mathrm{~mm} \mathrm{Hg}$ on at least two separate occasions or on diurnal IOP phasing. An individual participant's glaucoma diagnosis was defined by taking the clinically more serious diagnosis of either eye, in the following hierarchy (most serious to least serious): glaucoma, glaucoma suspect, ocular hypertension, narrow angle spectrum (primary angle closure, primary angle closure suspect and narrow angles) and normal. Self-reported data including family history of glaucoma, contact lens or glasses wear, eyesight problem and health status were all collected from a self-administered questionnaire.

\section{Statistical analysis}

Logistic regression was used to analyse the risk factors for previously undiagnosed POAG, with the dependent variable coded as $0=$ subjects with known POAG and $1=$ subjects with previously undiagnosed POAG. Factors that were significant $(\mathrm{p}<0.05)$ in the univariable analysis were included in the multivariable model in a stepwise backward model, and removed if $p<0.05$. The factors examined (box 1) included socioeconomic, demographic and systemic factors, as well as ocular factors that could affect a subject's likelihood of seeking eye care, such as presence of low visual acuity, previous cataract surgery, self-reported eyesight problems, high refractive error or wearing glasses/contact lens. Physical and economic factors that could present a barrier to eye care access, such as financial difficulty, physical frailty and poor health status were also included. Cup/disc ratio (CDR) and CDR asymmetry were multiplied by 10 in the regression models to allow the OR to be analysed per 0.1 increase in CDR. For ocular factors, the worse value of the two eyes were used for visual acuity, axial length (longer value) and central corneal thickness (lower value). For IOP, CDR and visual fields mean deviation, the value of the OAG eye was used; if both eyes had OAG then the worse value was used. All statistical analyses were performed using STATA (Stata/SE V.13.1).

\section{Pretreatment IOP and its imputation}

To allow unbiased comparison of IOP levels between the two groups, the pretreatment IOP was used for participants who have had pressure-lowering treatment. Pretreatment IOP is defined as the highest IOP (Goldmann applanation tonometry) documented in the patient's hospital records before any IOPlowering treatment (drops or surgery) was instigated. For those who have had IOP-lowering treatment but the pretreatment IOP was unavailable, the pretreatment IOP was imputed. Imputed IOP was not used in the diagnosis of NTG and HTG, which was made based on measured untreated IOP.

Among the 314 POAG participants in the study, 213 HTG eyes and 100 NTG eyes were on pressure-lowering treatment, defined as being on pressure-lowering medication and/or having undergone glaucoma surgery. In 114 HTG eyes and 42 NTG eyes the pretreatment IOP was available. Due to the high proportion of missing values (missing at random), they were imputed using multiple imputation by linear regression. The predictors were age, sex and OAG type (NTG vs HTG), and 100 iterations were imputed.

\section{RESULTS}

Out of the 8623 participants in the EPIC-Norfolk Eye Study, 363 participants were diagnosed with glaucoma in either eye; 314 of them had POAG. Among the 314 POAG subjects, 160 of them had HTG and 154 had NTG; 207 (65.9\%) were known cases, diagnosed before the start of the study and 107 (34.1\%) were previously undiagnosed. The mean age of the 314 participants was 74.2 years (range $49-90$ years) and $45 \%$ were women. Table 1 summarises the characteristics of the participants.

Table 2 shows the univariable logistic regression results comparing known POAG to previously undiagnosed POAG cases $(0=$ known POAG, $1=$ previously undiagnosed POAG). The factors associated with previously undiagnosed POAG in the univariable regression were: younger age, being currently employed, having NTG rather than HTG, lower pretreatment IOP, smaller CDR, visual field mean deviation, negative family history of glaucoma, reporting no problems with eyesight, being phakic rather than pseudophakic in either eye and higher absolute refractive error.

In the final multivariable model (table 3 ), subjects with previously undiagnosed POAG compared with those with a known diagnosis were more likely to have: a lower pretreatment IOP (OR $0.71 / \mathrm{mm} \mathrm{Hg}, 95 \%$ CI 0.63 to $0.80, \mathrm{p}<0.0001$ ), and to have reported no problems with their eyesight (OR 0.03, 95\% CI 0.01 to $0.69, \mathrm{p}<0.0001)$. The type of glaucoma was strongly associated with the pretreatment IOP, with the IOP being significantly lower among NTG than HTG patients (OR 0.63/mm Hg, $95 \%$ CI 0.55 to $0.72, \mathrm{p}<0.0001)$. 
Table 1 Characteristics of the previously known versus previously undiagnosed primary open angle glaucoma participants

\begin{tabular}{|c|c|c|c|}
\hline \multicolumn{2}{|l|}{ Characteristics median (IQR) or \% } & \multirow{2}{*}{$\begin{array}{l}\text { Previously diagnosed } \\
207\end{array}$} & \multirow{2}{*}{$\begin{array}{l}\text { Previously undiagnosed } \\
107\end{array}$} \\
\hline $\mathrm{n}$ & & & \\
\hline Age, years $(n=314)$ & & $72.8(67.0$ to 78.4$)$ & $75.4(70.3$ to 81.0$)$ \\
\hline \multirow{2}{*}{$\operatorname{Sex}(n=314)$} & Male & $52.2 \%$ & $61.7 \%$ \\
\hline & Female & $47.8 \%$ & $38.3 \%$ \\
\hline \multirow[t]{3}{*}{ Social class $(n=314)$} & Professional/managerial & $48.3 \%$ & $53.3 \%$ \\
\hline & Skilled (manual/non-manual) & $41.6 \%$ & $25.7 \%$ \\
\hline & Semi-skilled/unskilled & $10.1 \%$ & $21.0 \%$ \\
\hline \multirow[t]{4}{*}{ Education $(n=314)$} & No qualifications & $30.4 \%$ & $29.9 \%$ \\
\hline & O levels & $7.3 \%$ & $10.3 \%$ \\
\hline & A levels & $48.8 \%$ & $48.6 \%$ \\
\hline & Degree & $13.5 \%$ & $11.2 \%$ \\
\hline \multirow[t]{2}{*}{ Currently employed? $(n=310)$} & No & $89.3 \%$ & $79.8 \%$ \\
\hline & Yes & $10.7 \%$ & $20.2 \%$ \\
\hline \multirow[t]{2}{*}{ How often do you not have enough money for basics? $(n=293)$} & Never & $63.9 \%$ & $65.7 \%$ \\
\hline & Seldom/sometimes & $36.1 \%$ & $34.3 \%$ \\
\hline \multirow[t]{2}{*}{ POAG type $(n=314)$} & HTG & $69.1 \%$ & $15.9 \%$ \\
\hline & NTG & $30.9 \%$ & $84.1 \%$ \\
\hline $\operatorname{IOPg}(\mathrm{mm} \mathrm{Hg})(\mathrm{n}=307)$ & & $16.8(16.7$ to 18.2$)$ & $19.0(17.6$ to 19.4$)$ \\
\hline Pretreatment IOP $(\mathrm{mm} \mathrm{Hg})(\mathrm{n}=212)^{*}$ & & 26.7 .0 (25.9 to 27.5$)$ & $18.3(17.6$ to 19.1$)$ \\
\hline Axial length $(\mathrm{mm})(\mathrm{n}=286)$ & & $23.9(23.2$ to 25.1$)$ & $23.9(23.1$ to 24.8$)$ \\
\hline LogMAR visual acuity $(n=312)$ & & $0.20(0.16$ to 0.24$)$ & $0.08(0.0$ to 0.26$)$ \\
\hline Disc photo CDR $(n=249)$ & & $0.55(0.54$ to 0.57$)$ & $0.50(0.48$ to 0.53$)$ \\
\hline CDR asymmetry $(n=210)$ & & $0.06(0.02$ to 0.11$)$ & 0.07 (0.04 to 0.11$)$ \\
\hline Visual field mean deviation & & $-4.79(-7.72$ to 5.57$)$ & $-3.40(-4.63$ to -3.31$)$ \\
\hline Central corneal thickness $(\mu \mathrm{m})$ & & 535 (532 to 543$)$ & 544 (536 to 551$)$ \\
\hline \multirow[t]{2}{*}{ Family history of glaucoma $(n=269)$} & No & $64.0 \%$ & $77.7 \%$ \\
\hline & Yes & $36.0 \%$ & $22.3 \%$ \\
\hline \multirow[t]{2}{*}{ Wears glasses/contact lenses? $(n=308)$} & No & $2.5 \%$ & $0.96 \%$ \\
\hline & Yes & $97.6 \%$ & $99.0 \%$ \\
\hline \multirow[t]{2}{*}{ Do you have any problems with eyesight? $(n=298)$} & No & $11.5 \%$ & $75.5 \%$ \\
\hline & Yes & $88.5 \%$ & $24.5 \%$ \\
\hline \multirow[t]{2}{*}{ Pseudophakic in either eye $(n=314)$} & No & $62.3 \%$ & $85.1 \%$ \\
\hline & Yes & $37.7 \%$ & $15.0 \%$ \\
\hline Absolute refractive error (Dioptres) $(n=309)$ & & $1.81(0.75$ to 2.63$)$ & 1.25 (0.63 to 2.25$)$ \\
\hline Systolic BP (mm Hg) $(n=314)$ & & $137.5(135.5$ to 140.0$)$ & $140(135.8$ to 141.8$)$ \\
\hline Diastolic BP $(\mathrm{mm} \mathrm{Hg})(n=314)$ & & 76.5 (76.0 to 79.6$)$ & $79.0(76.4$ to 80.4$)$ \\
\hline BMI $\left(\mathrm{kg} / \mathrm{m}^{2}\right)(\mathrm{n}=313)$ & & $26.0(26.0$ to 27.0$)$ & 26.6 (26.1 to 27.6$)$ \\
\hline \multirow[t]{2}{*}{ Diabetes } & No & $97.1 \%$ & $98.1 \%$ \\
\hline & Yes & $2.9 \%$ & $1.9 \%$ \\
\hline \multirow[t]{4}{*}{ Self-reported health status $(n=312)$} & Excellent/very good & $37.4 \%$ & $33.0 \%$ \\
\hline & Good & $44.2 \%$ & $47.2 \%$ \\
\hline & Fair & $16.5 \%$ & $15.1 \%$ \\
\hline & Poor & $1.9 \%$ & $4.7 \%$ \\
\hline
\end{tabular}

Median $(95 \% \mathrm{Cl})$ shown for continuous variables.

*Unimputed data for pretreatment IOP.

BMI, body mass index; BP, blood pressure; HTG, high tension glaucoma; IOPg, Goldmann-correlated intraocular pressure; NTG, normal tension glaucoma.

Factors removed from the model in order were: age $(\mathrm{p}=0.52)$, being currently employed $(p=0.60)$, visual fields mean deviation $(p=0.40)$, pseudophakia in either eye $(p=0.76)$, absolute refractive error $(p=0.13)$, family history $(p=0.10)$, CDR $(p=0.12)$ and glaucoma type $(\mathrm{p}=0.09)$.

\section{DISCUSSION}

Among the social, economic, systemic and ocular factors examined, the two factors associated with undiagnosed POAG in the community were lower pretreatment IOP and the participants reporting no eyesight problems. The first points to an over-reliance on IOP level to exclude glaucoma in the community, leading to patients with lower IOP to be missed. The National Institute for Health and
Clinical Excellence guidelines in the UK recommend a referral to the Hospital Eye Service if IOP is greater than $24 \mathrm{~mm} \mathrm{Hg}$ in the absence of other risk factors, as ocular hypertension on its own may warrant treatment. ${ }^{9}$ Nevertheless, IOP has been shown to be an ineffective tool for glaucoma case finding in the EPIC-Norfolk Eye Study, and no single IOP level provides both high sensitivity and specificity in glaucoma diagnosis. ${ }^{8}$ This study demonstrates that it is easy for eye care providers to be reassured by an IOP level $<24 \mathrm{~mm} \mathrm{Hg}$, while other features of glaucoma are missed. It must be stressed therefore that among patients with non-elevated IOP, care should be taken to examine the optic disc carefully and with supportive disc imaging and visual field testing to improve the chances of identifying suspicious disc features. 
Table 2 Univariable logistic regression of previously diagnosed versus previously undiagnosed primary open angle glaucoma $(0=$ diagnosed $1=$ undiagnosed)

\begin{tabular}{|c|c|c|c|}
\hline Characteristics & & $\mathrm{OR}(95 \% \mathrm{Cl})$ & $P$ value \\
\hline Age, years & & 0.96 (0.93 to 0.99$)$ & 0.008 \\
\hline \multirow[t]{2}{*}{ Sex } & Male & 1.00 & \\
\hline & Female & 0.68 (0.42 to 1.09$)$ & 0.15 \\
\hline \multirow[t]{3}{*}{ Social class } & Professional/managerial & 1.00 & \\
\hline & Skilled (manual/non-manual) & 0.57 (0.33 to 0.98$)$ & 0.04 \\
\hline & Semi-skilled/unskilled & 1.84 (0.93 to 3.63 ) & 0.08 \\
\hline \multirow[t]{4}{*}{ Education } & No qualifications & 1.00 & \\
\hline & 0 levels & 1.44 (0.59 to 3.50$)$ & 0.42 \\
\hline & A levels & 1.01 (0.59 to 1.74$)$ & 0.96 \\
\hline & Degree & 0.84 (0.38 to 1.88$)$ & 0.68 \\
\hline \multirow[t]{2}{*}{ Currently employed? } & No & 1.00 & \\
\hline & Yes & 2.12 (1.10 to 4.06$)$ & 0.02 \\
\hline \multirow[t]{2}{*}{ How often do you not have enough money for basics? } & Never & 1.00 & \\
\hline & Seldom/sometimes & 0.93 (0.56 to 1.54$)$ & 0.77 \\
\hline \multirow[t]{2}{*}{ POAG type } & HTG & 1.00 & \\
\hline & NTG & 11.8 (6.52 to 21.5$)$ & $<0.0001$ \\
\hline IOPg (mm Hg) & & 1.04 (0.99 to 1.09$)$ & 0.08 \\
\hline Pretreatment IOP $(\mathrm{mm} \mathrm{Hg})^{*}$ & & 0.75 (0.69 to 0.82$)$ & $<0.0001$ \\
\hline Axial length (mm) & & 1.12 (0.94 to 1.34$)$ & 0.21 \\
\hline LogMAR visual acuity & & 0.86 (0.39 to 1.89$)$ & 0.70 \\
\hline Disc photo CDR ×10 & & 0.69 (0.55 to 0.87$)$ & 0.02 \\
\hline CDR asymmetry $\times 10$ & & 0.74 (0.48 to 1.15$)$ & 0.19 \\
\hline Visual field (MD) & & 1.14 (1.06 to 1.22$)$ & $\mathrm{p}<0.0001$ \\
\hline Central corneal thickness $(\mu \mathrm{m})$ & & 1.01 (0.99 to 1.01$)$ & 0.1 \\
\hline \multirow[t]{2}{*}{ Family history of glaucoma } & No & 1.00 & \\
\hline & Yes & $0.51(0.29$ to 0.91$)$ & 0.02 \\
\hline Wears glasses/contact & No & 1.00 & \\
\hline lenses? & Yes & 2.59 (0.30 to 22.4$)$ & 0.39 \\
\hline Do you have any problems & No & 1.00 & \\
\hline with eyesight? & Yes & 0.04 (0.02 to 0.08$)$ & $<0.0001$ \\
\hline \multirow[t]{2}{*}{ Pseudophakic in either eye } & No & 1.00 & \\
\hline & Yes & 0.29 (0.16 to 0.53$)$ & $<0.0001$ \\
\hline Absolute refractive error (Dioptres) & & 1.16 (1.01 to 1.33$)$ & 0.03 \\
\hline Systolic BP (mm Hg) & & 1.00 (0.99 to 1.02$)$ & 0.60 \\
\hline Diastolic BP (mm Hg) & & 1.01 (0.99 to 1.04$)$ & 0.32 \\
\hline BMI $\left(\mathrm{kg} / \mathrm{m}^{2}\right)$ & & 1.02 (0.96 to 1.08$)$ & 0.50 \\
\hline \multirow[t]{2}{*}{ Diabetes } & No & 1.00 & 0.59 \\
\hline & Yes & 0.64 (0.13 to 3.22$)$ & \\
\hline \multirow[t]{4}{*}{ Self-reported health status } & Excellent/very good & 1.00 & \\
\hline & Good & 1.21 (0.71 to 2.05$)$ & 0.48 \\
\hline & Fair & 1.04 (0.51 to 2.12 ) & 0.93 \\
\hline & Poor & $2.75(0.70$ to 10.9$)$ & 0.15 \\
\hline
\end{tabular}

*Imputed data.

CDR, cup/disc ratio; HTG, high tension glaucoma; IOP, intraocular pressure; NTG, normal tension glaucoma; POAG, primary open angle glaucoma.

In this study, other features of severity of glaucoma such as vertical CDR and visual field mean deviation were not associated with missed OAG cases. It could be because CDR does not adequately capture features of a glaucomatous disc, and visual

Table 3 Multivariable regression of previously diagnosed versus previously undiagnosed primary open angle glaucoma ( $0=$ diagnosed $1=$ undiagnosed)

\begin{tabular}{llll}
\hline Characteristics & OR $(95 \% \mathrm{Cl})$ & P value \\
\hline Pretreatment IOP $(\mathrm{mm} \mathrm{Hg})^{*}$ & & $0.71(0.63$ to 0.80$)$ & $<0.0001$ \\
Do you have any problems with eyesight? & No & 1.00 & $<0.0001$ \\
& Yes & $0.03(0.01$ to 0.69$)$ & \\
\hline
\end{tabular}

*Imputed data.

IOP, intraocular pressure. fields may not be done routinely at the optician. Even with advanced field defects, many patients with glaucoma are asymptomatic, so field defects will not necessarily provide a reason to visit the optician.

Several factors were examined that could reflect a participant's access or likelihood to seek eye care. An important limitation of the methodology is that specific questions about the participants' history of visits to eye care professionals were not collected prospectively, and asking the questions retrospectively would be prone to recall bias and significant inaccuracies. Hence, there was the need to use proxy factors, such as absolute refractive error, glasses use, being pseudophakic and self-reported visual problems, which require careful interpretation. The strongest factor associated with undiagnosed POAG was answering no to the question 'do you have problems with your eyesight', 
while worse acuity of either eye was not related. A possible interpretation of this finding is that it was the self-perception of good eyesight, and by implication, a lesser likelihood to visit an optometrist, rather than actual visual function, that led the POAG to be undiagnosed. Nevertheless, the participants with existing glaucoma might have perceived their eyesight as being worse than those with undiagnosed glaucoma as a recall bias, as they had a known eye condition, or the use of eyedrops or having had eye surgery diminished their visual function. Wearing glasses or contact lenses was not a significant factor, most likely because $97 \%$ of the cohort wore glasses, and it was not effective in discriminating those with previously diagnosed and undiagnosed POAG.

Published studies have explored the question whether visits to eye care professionals is important in facilitating the discovery of glaucoma. The Thessaloniki Study found that previously undiagnosed patients were more likely to not have seen an eye doctor in the past year. ${ }^{4}$ Similarly, both the Barbados Eye Study ${ }^{3}$ and the Melbourne Visual Impairment Project ${ }^{5}$ reported that previously undiagnosed patients sought eye care less frequently in the past year, with the source of eye care more likely to be an optometrist rather than an ophthalmologist. ${ }^{35}$ However, these findings are potentially confounded by the fact that patients with diagnosed glaucoma would already be under the care of an ophthalmologist, so a prospective study is required to adequately answer that question.

Currently in the UK, POAG is diagnosed by opportunistic case finding, relying on patients presenting to an optometrist for an eye test, and referral made to the Hospital Eye Service under the National Health Service if glaucoma is suspected. Those most at risk of glaucoma-aged $>60$ and those aged $>40$ with a positive family history of glaucoma in a first degree relative-can get the optician's eye test for free, and so there is no financial barrier to the diagnosis of glaucoma among those at risk. In EPICNorfolk, a greater proportion of all glaucoma cases (67\%) were previously diagnosed, compared with the usual $50 \%$ reported in most western population studies. There are a few potential explanations. First, due to the method of recruitment and the low proportion of retained participants from the original cohort, the study population was not representative of the general population of Norfolk and UK. They were older, with an overrepresentation of those above age 60 , the age from which eye tests are free at the optician, therefore biasing the likelihood of them visiting an optician. Another explanation could be recruitment bias, as health conscious individuals who were more likely to visit their optician were also more likely to participate in this study. It might also reflect more effective healthcare provision in Norfolk. However, one cannot discount the possibility that some participants who were known patients with glaucoma were motivated to take part by an enthusiasm to have additional eye testing, causing response bias.

In conclusion, the most important healthcare implication from this analysis is to avoid being falsely reassured by a lower level of IOP in glaucoma case finding. There is also a suggestion that raising public awareness of glaucoma and encouraging regular eye tests at the optician can help reduce undiagnosed glaucoma.
Acknowledgements We thank Dr Haogang Zhu for his help in extracting visual field data, and Mr Pak Sang Lee for his technical assistance with the EPIC-Norfolk Eye Study.

Contributors MPYC designed and performed the analysis and drafted the manuscript. APK and JY contributed to data collection and interpretation. DCB, PJF and K-TK contributed to the design of the EPIC-Norfolk Eye Study and DCB and PJF contributed to data collection and interpretation. RL contributed to data management. SH contributed to the running of the EPIC-Norfolk Eye Study.TP contributed to disc photo grading in the EPIC-Norfolk Eye Study.

Funding EPIC-Norfolk infrastructure and core functions are supported by grants from the Medical Research Council (G0401527) and Cancer Research UK (C864) A8257). The clinic for the third health examination was funded by Research into Ageing (262). MPYC was funded by an MRC/RCOphth Clinical Training Fellowship (G1001939/1) and the International Glaucoma Association. APK is funded by a Moorfields Eye Charity fellowship. JY was funded by a NIHR clinical lectureship. PJF was supported by the Richard Desmond Charitable Trust via Fight for Sight (1956), the Special Trustees of Moorfields Eye Hospital (ST 12 09) and the Department for Health through the award made by the NIHR Biomedical Research Centre at Moorfields Eye Hospital NHS Foundation Trust (BRC3_026). The funding organisations had no role in the design or conduct of this research.

Competing interests None declared.

\section{Patient consent for publication Not required.}

Ethics approval The work was carried out with the approval of the East Norfolk and Waverney NHS Research Governance Committee (2005EC07L) and the Norfolk Research Ethics Committee (05/Q0101/191), in accordance with the principles of the Declaration of Helsinki.

Provenance and peer review Not commissioned; externally peer reviewed.

Data availability statement Data are available upon reasonable request. All data relevant to the study are included in the article or uploaded as supplementary information. All data relevant to the study are included in the article or uploaded as supplementary information. Data are available upon reasonable request

Open access This is an open access article distributed in accordance with the Creative Commons Attribution 4.0 Unported (CC BY 4.0) license, which permits others to copy, redistribute, remix, transform and build upon this work for any purpose, provided the original work is properly cited, a link to the licence is given, and indication of whether changes were made. See: https://creativecommons.org/ licenses/by/4.0/.

\section{ORCID iDs}

Michelle P Y Chan http://orcid.org/0000-0003-4058-4234

Anthony P Khawaja http://orcid.org/0000-0001-6802-8585

Robert Luben http://orcid.org/0000-0002-5088-6343

Tunde Peto http://orcid.org/0000-0001-6265-0381

\section{REFERENCES}

1 Dielemans I, Vingerling JR, Wolfs RC, et al. The prevalence of primary open-angle glaucoma in a population-based study in the Netherlands. The Rotterdam study. Ophthalmology 1994;101:1851-5.

2 Mitchell P, Smith W, Attebo K, et al. Prevalence of open-angle glaucoma in Australia. the blue Mountains eye study. Ophthalmology 1996;103:1661-9.

3 Hennis A, Wu S-Y, Nemesure B, et al. Awareness of incident open-angle glaucoma in a population study: the Barbados eye studies. Ophthalmology 2007;114:1816-21.

4 Topouzis F, Coleman AL, Harris A, et al. Factors associated with undiagnosed openangle glaucoma: the Thessaloniki eye study. Am J Ophthalmol 2008;145:327-35.

5 Wong EYH, Keeffe JE, Rait JL, et al. Detection of undiagnosed glaucoma by eye health professionals. Ophthalmology 2004;111:1508-14.

6 Day N, Oakes S, Luben R, et al. Epic-Norfolk: study design and characteristics of the cohort. European prospective investigation of cancer. Br J Cancer 1999;80:95-103.

7 Khawaja AP, Chan MPY, Hayat S, et al. The EPIC-Norfolk eye study: rationale, methods and a cross-sectional analysis of visual impairment in a population-based cohort. BMJ Open 2013;3:e02684

8 Chan MPY, Broadway DC, Khawaja AP, et al. Glaucoma and intraocular pressure in EPIC-Norfolk eye study: cross sectional study. BMJ 2017;358:j3889.

9 National Institute for Health and Care Excellence. Glaucoma: diagnosis and management (NG81), 2017. 